\title{
Changes in thioredoxin concentrations: an observation in an ultra-marathon race
}

\author{
Mitsuhiro Marumoto $\cdot$ Sadao Suzuki • Akihiro Hosono $\cdot$ Kazuyuki Arakawa \\ Kiyoshi Shibata • Mizuho Fuku • Chiho Goto • Yuko Tokudome $\cdot$ Hideki Hoshino • \\ Nahomi Imaeda $\cdot$ Masaaki Kobayashi $\cdot$ Junji Yodoi $\cdot$ Shinkan Tokudome
}

Received: 16 August 2009/Accepted: 27 October 2009/Published online: 4 December 2009

(C) The Japanese Society for Hygiene 2009

\begin{abstract}
Objectives Changes in plasma thioredoxin (TRX) concentrations before, during, and after a $130-\mathrm{km}$ endurance race were measured with the aim of elucidating the relationship between exercise and oxidative stress (OS).

Methods Blood samples were taken from 18 runners participating in a 2-day-long 130-km ultra-marathon during the 2 days of the race and for 1 week thereafter. There were six sampling time points: at baseline, after the goal had been reached on the first and second day of the endurance race, respectively, and on 1, 3, and 5/6 days post-endurance race. The samples were analyzed for plasma TRX concentrations, platelet count, and blood lipid profiles.

Results Concentrations of plasma TRX increased from $17.9 \pm 1.2 \mathrm{ng} / \mathrm{mL}$ (mean \pm standard error of the mean) at
\end{abstract}

\footnotetext{
M. Marumoto · S. Suzuki · A. Hosono - K. Arakawa ·

S. Tokudome

Department of Public Health, Nagoya City University Graduate

School of Medical Sciences, Nagoya, Japan

e-mail: Marumoto_Mitsuhiro@ takeda.co.jp

K. Shibata

Kasugai City Health Care Center, Kasugai, Japan

M. Fuku

Yokohama City University Medical Center, Yokohama, Japan

C. Goto

Nagoya Bunri University, Inazawa, Japan

Y. Tokudome

Nagoya University of Arts and Sciences, Nisshin, Japan

H. Hoshino

Aichi Bunkyo Women's College, Inazawa, Japan
}

baseline to $57.3 \pm 5.0 \mathrm{ng} / \mathrm{mL}$ after the first day's goal had been reached and to $70.1 \pm 6.9 \mathrm{ng} / \mathrm{mL}$ after the second day's goal had been reached; it then returned to the baseline level 1 day after the race. Platelet counts of $21.3 \pm$ $1.2 \times 10^{4} \mathrm{cell} / \mu \mathrm{L}$ at baseline increased to $23.9 \pm 1.5 \times$ $10^{4}$ cells $/ \mu \mathrm{L}$ on Day 1 and to $26.1 \pm 1.0 \times 10^{4}$ cells $/ \mu \mathrm{L}$ on Day 2. On Day 7, the platelet counts had fallen to $22.1 \pm 1.2 \times 10^{4} \mathrm{cell} / \mu \mathrm{L}$. There was a significant positive correlation between plasma TRX and platelet count.

Conclusions These data suggest that plasma TRX is an OS marker during physical exercise. Further studies are needed to determine the appropriate level of exercise for the promotion of health.

Keywords Lipid profile - Marathon runner . Oxidative stress $\cdot$ Platelet counts $\cdot$ Thioredoxin

\author{
N. Imaeda \\ Nagoya Women's University, Nagoya, Japan \\ M. Kobayashi \\ Department of Bone and Orthopedics, Nagoya City University \\ Graduate School of Medical Sciences, Nagoya, Japan \\ J. Yodoi \\ Department of Biological Responses, Institute for Virus \\ Research, Kyoto University, Kyoto, Japan \\ S. Tokudome $(\square)$ \\ National Institute of Health and Nutrition, 1-23-1 Toyama, \\ Shinjuku-ku, Tokyo 162-8636, Japan \\ e-mail: tokudome@nih.go.jp
}




\section{Introduction}

Moderate physical exercise is believed to be beneficial to health by reducing the risk of several diseases, including cardiovascular problems and diabetes mellitus. However, it has been suggested that extreme endurance exercise may be detrimental because reactive oxygen species (ROS) are generated by excessive oxygen consumption [1]. Oxidative stress (OS) can be defined as "an imbalance between the free radical production and antioxidant defense mechanisms of a biological organism that results, directly or indirectly, in cellular damage" [2].

The human body is protected by anti-oxidant systems, including that of thioredoxin (TRX) [3]. TRX is a ubiquitous small protein $(12 \mathrm{kDa})$ that acts as an antioxidant via a cysteine thiol-disulfide exchange in which it functions as a proton donor. This function is dependent on the cyclic reduction-oxidation of a single $\mathrm{S}-\mathrm{S}$ bond. When the reduced form of TRX [TRX-(SH) $)_{2}$ captures ROS, it is transformed into oxidized-TRX (TRX-S $)_{2}$ and $\mathrm{H}_{2} \mathrm{O}$. Oxidized-TRX is then reduced by TRX reductase to become reduced-TRX [4]. This redox reaction suggested that TRX plays an important role as an antioxidant [5].

TRX has been reported to be a sensitive OS marker, with its levels increasing in relation to hydrogen peroxide, ultraviolet irradiation, and inflammation $[3,4,6]$. It is associated with the signal transduction of cellular redox regulation and with cytoprotection against OS [3]. Elevated plasma TRX concentrations suggest not only an elevated level of OS, but also enhancement of the anti-oxidative system through the activation of TRX gene expression [7].

TRX was originally purified from Escherichia coli in 1964 as a proton donor to ribonucleotide reductase, and it was thought to be a regulator of cellular redox status [8]. In 1989, Yodoi's group identified the adult T-cell leukemia-derived factor as TRX [9], originally defined as an interleukin-2 receptor $\alpha$-chain inducer in human T-lymphotropic virus type I-transformed cells. TRX has both extra- and intra-cellular functions, and it is one of the key signaling regulators in the cellular response to various OS. It is also associated with the redox regulation of cellular activation and redox-sensitive molecules, such as NF-kB, AP-1, and glucocorticoid receptors, indicating both antioxidant and effects $[4,10,11]$.

Results from earlier studies suggested that extreme exercise elevates OS markers, including urinary 8-hydroxydeoxyguanosines (8-OHdG), oxidized DNA nucleosides [8, 12, 13], malondialdehydes, isoprostanes, and lipid peroxides (LPO) $[2,14]$. Intense physical exercise was also found to increase the plasma concentrations of free fatty acids (FFA) and fatty acid oxidation [15]. Plasma FFA are used as an energy source and are also associated with the generation of OS through lipid peroxidation.
To the best of our knowledge, no data have been reported on the variations in plasma TRX concentrations during physical exercise. Here, we report our analysis of changes in plasma TRX concentrations in participants in an ultra-marathon, based on blood samples taken before, during, and after the race, and our comparison of these changes with the lipid profile.

\section{Subjects and methods}

Ultra-marathon race

A non-competitive ultra-marathon race was held in Gifu Prefecture, Japan, on July 24-25, 2004 [16]. The race covered a distance of $130 \mathrm{~km}$ and comprised running and mountaineering activities over the 2-day period. On the first day, at 11 a.m., the participants began a full-length marathon race to be completed within $6.5 \mathrm{~h}$. At 3:30 a.m. on the second morning, they resumed the race, covering approximately $90 \mathrm{~km}$, including climbing a mountain approximately $1100 \mathrm{~m}$ high, then returning to the starting point within $15.5 \mathrm{~h}$. It was very hot and sultry during the race, with the temperature hovering around $35.5^{\circ} \mathrm{C}$. There were no dietary restrictions during the race, and runners were free to take any food and beverage of their choice.

\section{Subjects}

Non-professional Japanese male athletes participated in our study. We asked 41 runners to participate in our analysis, of whom 24 agreed. We received written informed consent for their completion of lifestyle questionnaires, measurements of anthropometric characteristics, and blood sampling. The protocol was approved by the Institutional Review Board of Nagoya City University Graduate School of Medical Sciences and by the chairman and organizing committee of the race.

Anthropometric measurements and blood sampling

Anthropometric measurements and the sampling of venous blood were performed at six time points: i.e., before the race (baseline), immediately after completing the first stage (Day 1) and after completing the final stage (Day 2), early morning 1 day after the race (Day 3), 3 days after the race (Day 5), and 5 or 6 days after the race (Day 7) (Fig. 1). About $1-2 \mathrm{~h}$ before the race, we obtained spot (non-fasting) venous blood using a vacuum tube with serum separating medium (Tube 1) and with EDTA-2Na (Tube 2) and the anthropometric data. Immediately after the participants finished the race on Day 1 and Day 2, respectively, we obtained spot venous blood samples using the same 
Fig. 1 Study protocol. Anthropometric measurements and blood samplings were performed at six time points: before the race (baseline), after completing the first stage (DAY 1), after completing the final stage (DAY 2), and 1 day (DAY 3), 3 days (DAY 5), and 5/6 days $(D A Y 7)$ after the race

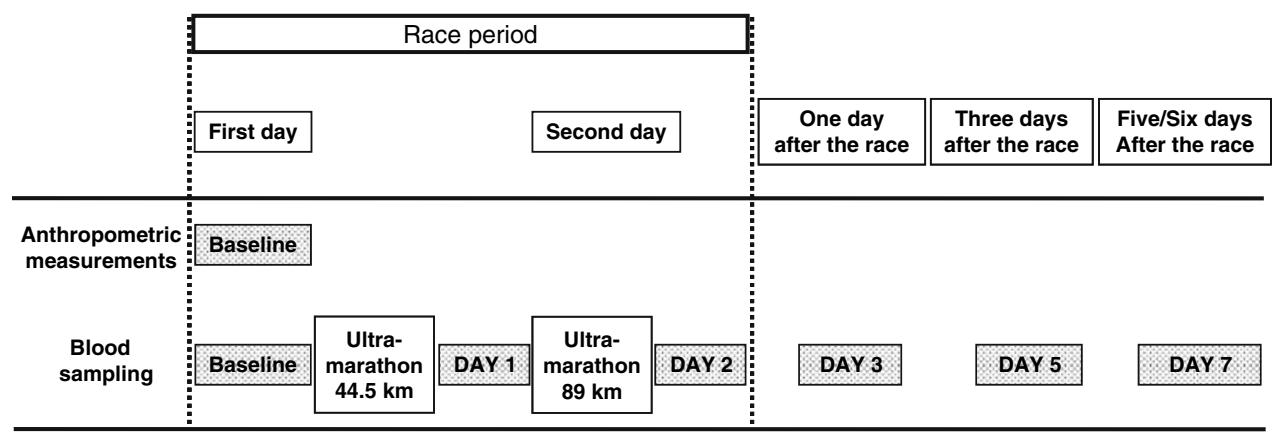

procedure as for the baseline samples. The tubes from all three samplings (baseline, Days 1 and 2) were kept in an ice-cooled box for several hours and then transported to a commercial laboratory on the same day. Early morning (about 7:30-8:00 a.m.) fasting blood was sampled on Days 3, 5, and 7, respectively. Tube 1 was centrifuged into serum and analyzed for biochemical markers, including hematocrit, platelet, hemoglobin $(\mathrm{Hb})$, total protein, FFA, triglycerides, total cholesterol, and high-density lipoprotein cholesterol (HDL-cholesterol) using a Hitachi 7600 machine (Hitachi High-Tech K.K., Tokyo, Japan). Tube 2 was separated into plasma, buffy coat, and red blood cell (RBC) fractions and then stored in a deep freezer $\left(-80^{\circ} \mathrm{C}\right)$ until analysis for plasma TRX.

\section{Measurements of TRX}

All plasma TRX concentrations, including reduced- and oxidized-TRX, were determined with a sensitive sandwich enzyme-linked immunosorbent assay (ELISA) kit (Redox Bioscience, Kyoto, Japan), as reported elsewhere [17]. Human TRX-antibody-precoated 96-microwell plates were incubated for $2 \mathrm{~h}$ at room temperature with $25 \mu \mathrm{L}$ of plasma or with a standard solution (human TRX antigen; $0,2.5,5,10,20,40,80,160 \mathrm{ng} / \mathrm{mL})$ in the presence of $250 \mu \mathrm{L}$ of $50 \mathrm{mmol} / \mathrm{L}$ sodium phosphate buffer $(\mathrm{pH} 6.0)$ containing $150 \mathrm{mmol} / \mathrm{L} \mathrm{NaCl}, 1.0 \mathrm{mmol} / \mathrm{L} \mathrm{Mg} \mathrm{Cl} 2,1.0 \%$ bovine serum albumin (BSA), and $0.1 \% \mathrm{NaN}_{3}$. The plates were washed five times with $10 \mathrm{mmol} / \mathrm{L}$ sodium phosphate buffer ( $\mathrm{pH}$ 7.5) containing $0.05 \%$ Tween 20 and $150 \mathrm{mmol} / \mathrm{L} \mathrm{NaCl}$ (Washing Solution), $200 \mu \mathrm{L}$ horseradish peroxidase-labeled anti-human TRX antibody was then added, and the plates were incubated at room temperature for $2 \mathrm{~h}$. After a further five washings with Washing Solution, we introduced $100 \mu \mathrm{L}$ of $100 \mathrm{mmol} / \mathrm{L}$ triethanolamine-succinate buffer ( $\mathrm{pH} 4.4$ ) containing $1.5 \mathrm{mmol} / \mathrm{L}$ $\mathrm{H}_{2} \mathrm{O}_{2}$ and $0.13 \%$ ABTS [2,2'-azino-di (3-ethylbenzthiazoline sulfonic acid)]. Incubation at room temperature was continued for $30 \mathrm{~min}$. The reaction was stopped by adding $100 \mu \mathrm{L}$ of $0.25 \mathrm{M} \mathrm{H}_{2} \mathrm{SO}_{4}$ solution, and the optical density of the plates was measured at $450 / 620 \mathrm{~nm}$ with a microplate reader (Spectramax 340; Molecular Devices, Sunnyvale, CA). All assessments were made in triplicate, and the average value was calculated.

Statistical analysis

Data are expressed as mean with standard deviation (SD) to show the distribution of baseline values, or as the standard error of the mean (SEM) to demonstrate the difference of means. The general linear model (GLM procedure) along with the post hoc Dunnett's test was applied to detect statistical significance at $p<0.05$ in comparison with each time point. The SAS ver. 9.1 software package (SAS Institute, Cary, NC) was used for the statistical analyses.

\section{Results}

Of the 24 runners included in the study, 18 completed the race and six dropped out during the race. All 18 were non-smokers. In terms of anthropometric and demographic measures (Table 1), the average age of the 18 runners was $54 \pm 12$ years (mean $\pm \mathrm{SD}$ ), and their average body mass index (BMI) was $21.4 \pm 1.6 \mathrm{~kg} / \mathrm{m}^{2}$. These runners had a recent average monthly running distance of $247.5 \pm$ $96.8 \mathrm{~km}$. In this race, their average completion time for the 2-day ultra-marathon race was $1,106.0 \pm 179.0 \mathrm{~min}$ (range 711.0 to $1,313.0 \mathrm{~min}$ ).

The hematocrit rose significantly from $42.3 \pm 0.7 \%$ (mean $\pm \mathrm{SEM}$ ) at baseline to $43.9 \pm 0.7 \%$ on Day 1 , returning to $43.0 \pm 0.5 \%$ by Day 2 . The $\mathrm{Hb}$ count was $14.4 \pm 0.3 \mathrm{~g} / \mathrm{dL}$ at baseline, increasing significantly to $15.1 \pm 0.3 \mathrm{~g} / \mathrm{dL}$ on Day 1 , but returning to $14.8 \pm 0.2 \mathrm{~g} / \mathrm{dL}$ on Day 2. A platelet count of $21.3 \pm 1.2 \times 10^{4} \mathrm{cell} / \mu \mathrm{L}$ was found at baseline; it increased to $23.9 \pm 1.5 \times 10^{4}$ cell $/ \mu \mathrm{L}$ on Day 1 (Fig. 2) and to $26.1 \pm 1.0 \times 10^{4}$ cell $/ \mu \mathrm{L}$ on Day 2 . On Day 7, the platelet count had fallen to $22.1 \pm 1.2 \times$ $10^{4} \mathrm{cell} / \mu \mathrm{L}$. There was a significant positive correlation between plasma TRX levels and platelet counts $(r=0.318$, $p<0.01$ ) (Fig. 3). The total protein level of $7.1 \pm 0.1 \mathrm{~g} / \mathrm{dL}$ at baseline rose significantly to $7.6 \pm 0.1 \mathrm{~g} / \mathrm{dL}$ on Day 1 and 
Table 1 Baseline characteristics of 18 subjects who completed the 2-day ultra-marathon

\begin{tabular}{lc}
\hline Characteristic & Mean $\pm \mathrm{SD}$ \\
\hline Age & $54 \pm 12$ \\
Body mass index $\left(\mathrm{kg} / \mathrm{m}^{2}\right)$ & $21.4 \pm 1.6$ \\
White blood cell count $\left(\times 10^{3} \mathrm{cell} / \mu \mathrm{L}\right)$ & $4.85 \pm 1.00$ \\
Red blood cell count $\left(\times 10^{5} \mathrm{cell} / \mu \mathrm{L}\right)$ & $4.47 \pm 0.40$ \\
Hemoglobin $(\mathrm{g} / \mathrm{dL})$ & $14.4 \pm 1.1$ \\
Hematocrit $(\%)$ & $42.3 \pm 2.8$ \\
Platelet count $\left(\times 10^{4}\right.$ cell $\left./ \mu \mathrm{L}\right)$ & $21.3 \pm 5.1$ \\
Total protein $(\mathrm{g} / \mathrm{dL})$ & $7.10 \pm 0.40$ \\
BUN $(\mathrm{mg} / \mathrm{dL})$ & $16.7 \pm 4.6$ \\
Uric acid $(\mathrm{mg} / \mathrm{dL})$ & $6.10 \pm 1.10$ \\
Total cholesterol $(\mathrm{mg} / \mathrm{dL})$ & $210 \pm 27$ \\
HDL cholesterol $(\mathrm{mg} / \mathrm{dL})$ & $81.0 \pm 18.3$ \\
Free fatty acids $(\mathrm{mEq} / \mathrm{L})$ & $0.120 \pm 0.100$ \\
Triglycerides $(\mathrm{mg} / \mathrm{dL})$ & $118 \pm 83$ \\
\hline BUN Blood
\end{tabular}

$B U N$ Blood urea nitrogen, $H D L$ high-density lipoprotein

Data are expressed as the mean \pm standard deviation (SD)
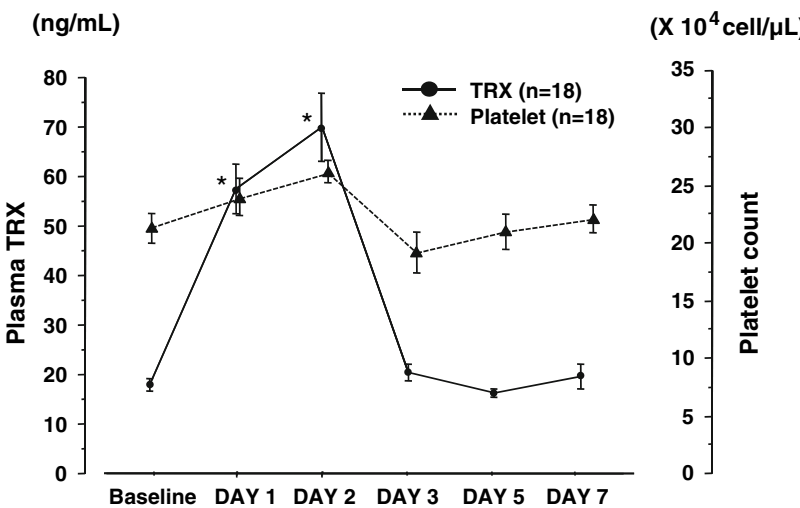

Fig. 2 Changes in plasma thioredoxin (TRX) and platelet counts throughout the study period. Solid line with filled circles Plasma TRX concentrations, dotted line with filled triangles platelet counts. Data are given as the mean \pm standard error of the mean (SEM). $* p<0.05$ denotes a significant difference from the baseline value

returned to $7.3 \pm 0.1 \mathrm{~g} / \mathrm{dL}$ on Day 2 . In order to adjust the effects of dehydration [18], we multiplied the levels of TRX, FFA, platelet count, total cholesterol, HDL-cholesterol, and triglycerides by the ratio of the hematocrit at baseline/its value at five of the six time points (excluding baseline sampling).

The average baseline plasma TRX level of $17.9 \pm$ $1.2 \mathrm{ng} / \mathrm{mL}$ increased significantly to $57.3 \pm 5.0 \mathrm{ng} / \mathrm{mL}$ on Day 1 ( $p<0.05$ vs. baseline value). On Day 2 it rose to fourfold the baseline concentration $(70.1 \pm 6.9 \mathrm{ng} / \mathrm{mL}$, $p<0.05)$, then decreased to $20.4 \pm 1.7 \mathrm{ng} / \mathrm{mL}$ on Day 3 (not significantly different from the baseline value), stabilizing around that level on Days 5 and 7 (Figs. 2, 4).

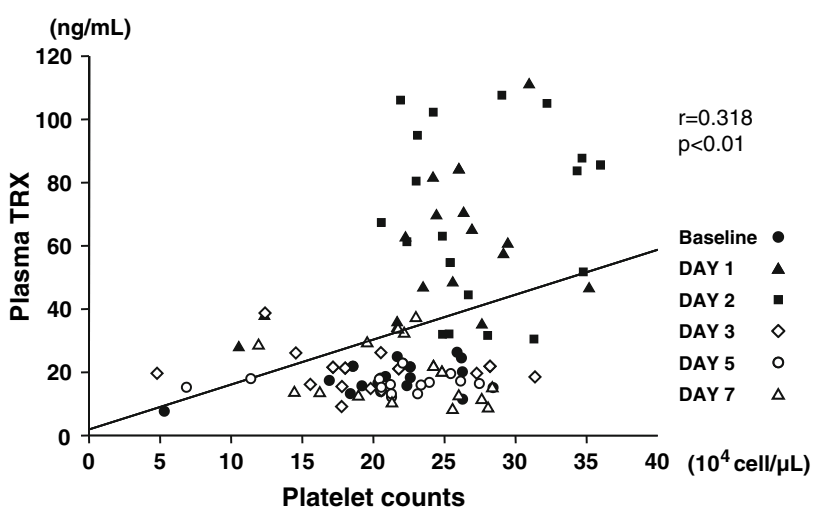

Fig. 3 Correlation between plasma TRX and platelet counts throughout the study period

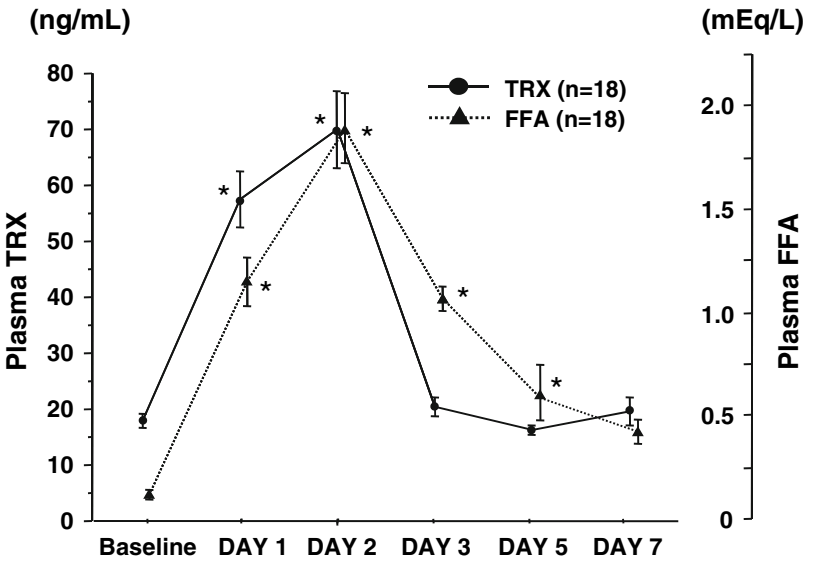

Fig. 4 Changes in plasma TRX and serum free fatty acids (FFA) concentrations throughout the study period. Solid line with filled circles Plasma TRX concentrations, dotted line with filled triangles plasma FFA levels. Data are expressed as the mean \pm SEM. $* p<0.05$ denotes a significant difference from the baseline value

In terms of the lipid profiles, the plasma FFA level of $0.12 \pm 0.02 \mathrm{mEq} / \mathrm{L}$ at baseline increased significantly to $1.15 \pm 0.12 \mathrm{mEq} / \mathrm{L}$ on Day 1 ( $p<0.05$ vs. baseline value) (Fig. 4) and $1.89 \pm 0.17 \mathrm{mEq} / \mathrm{L}$ on Day $2(p<0.05)$ before declining on Day 3, reaching $0.42 \pm 0.06 \mathrm{mEq} / \mathrm{L}$ on Day 7. There was a significant positive correlation between plasma TRX and plasma FFA concentrations $(r=0.647, p<0.0001)$ (Fig. 5).

The triglyceride level was $118.3 \pm 19.5 \mathrm{mg} / \mathrm{dL}$ at baseline, declining gradually to $46.0 \pm 5.4 \mathrm{mg} / \mathrm{dL}$ on Day 2 ( $p<0.05$ vs. baseline value) and to $40.3 \pm 4.2 \mathrm{mg} / \mathrm{dL}$ on Day $3(p<0.05)$ (Fig. 6) and then returning to baseline on Day 5 and Day 7. The total cholesterol level of $210.5 \pm 6.4 \mathrm{mg} / \mathrm{dL}$ at baseline rose slightly to $219.8 \pm$ $6.9 \mathrm{mg} / \mathrm{dL}$ on Day 1 and then declined to $199.1 \pm 7.1 \mathrm{mg} /$ dL on Day 3. There was a significant difference in total cholesterol levels on Day $7(p<0.05)$. The HDL-cholesterol level of $81.0 \pm 4.3 \mathrm{mg} / \mathrm{dL}$ at baseline significantly 


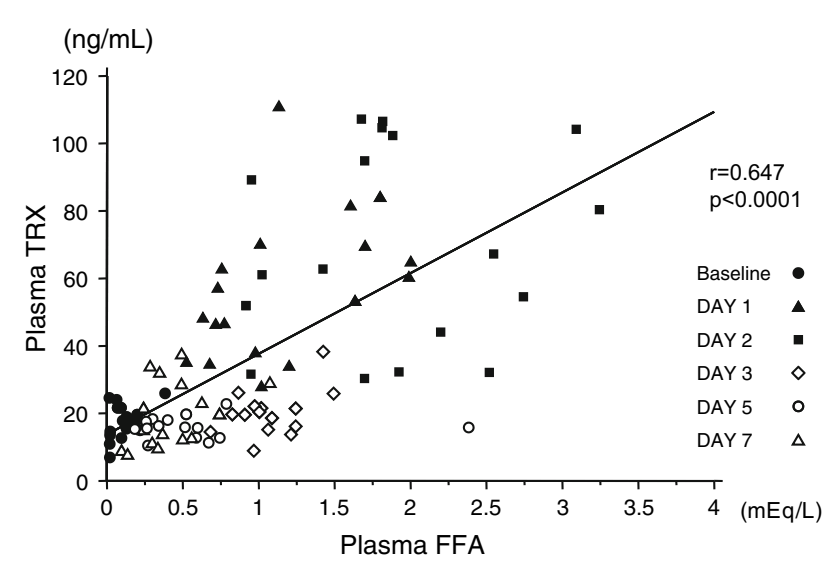

Fig. 5 Correlation between plasma TRX levels and log plasma FFA concentrations throughout the study period

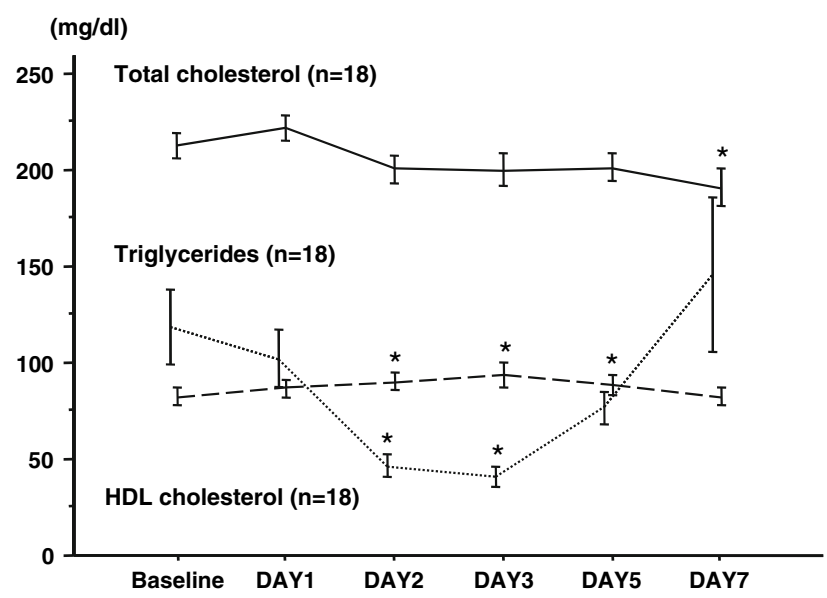

Fig. 6 Changes in lipid profiles throughout the study period. Dotted line Serum triglyceride concentrations, solid line total cholesterol concentrations, broken line high-density lipoprotein (HDL)-cholesterol. Data are expressed as the mean \pm SEM. $* p<0.05$ denotes a significant difference from the baseline value

increased to $92.5 \pm 6.0 \mathrm{mg} / \mathrm{dL}$ on Day 2 ( $p<0.05$ vs. baseline value), but it had returned to the baseline value $(80.9 \pm 4.6 \mathrm{mg} / \mathrm{dL})$ by Day 7 .

\section{Discussion}

Our analysis of the plasma OS in marathon runners participating in a 2-day $130-\mathrm{km}$ competition showed a continuous increase in plasma TRX concentrations during this extreme endurance exercise when adjustments were made for the effects of plasma volume change. The change in plasma FFA concentrations resembled that of plasma TRX levels, and there was a significant correlation between TRX and FFA levels, suggesting that plasma TRX is a useful OS marker.
We found that plasma triglycerides decreased steadily regardless of what foods/beverages were consumed during the race, but that they recovered 5/6 days after the race, as has been described earlier [19]. Most fat is stored as triglycerides in the subcutaneous and visceral fat tissues, and the latter are taken up by the skeletal muscle cells as FFA during exercise [20]. Plasma FFA subsequently become the major source of energy during exercise, indicating a reduction in plasma triglycerides. In agreement with this, we found that plasma total cholesterol gradually declined during and after the race.

A significant correlation between the plasma TRX level and platelet count has been reported earlier, with the presence of TRX in platelets confirmed by immunochemical methods [21]. In a later study, Miyamoto et al. [22] reported that the plasma TRX level relates significantly to platelet aggregability in patients with acute myocardial infarction. In our study, we found a significant positive correlation between plasma TRX level and platelet counts, suggesting that TRX is derived from the platelets. However, we did not measure platelet aggregability.

There have been many studies on OS using several markers, including urinary $8-\mathrm{OHdG}$, malondialdehydes, and plasma isoprostanes [2, 14, 22-24]. Studies on urinary 8-OHdG concentrations among healthy subjects, however, indicate that the range is narrow even in ultra-marathon runners [13, 24]. In contrast, we found that TRX is an OS marker that shows distinct changes in the blood.

ROS are generated by excess oxygen consumption during physical exercise. It is, however, difficult to detect ROS directly because they are highly labile and unstable. We analyzed TRX levels before, during, and after an ultramarathon race and observed a significant increment in plasma TRX concentrations among ultra-marathon runners. Based on these results, it may be concluded that TRX is a useful OS marker during physical exercise. Further studies of TRX are therefore needed to investigate an appropriate level of physical exercise, including jogging, for the purpose of promoting good health.

Acknowledgments This study was supported, in part, by a Grantin-Aid from the Ministry of Education, Culture, Sports, Science, and Technology, Japan. We thank the runners who willingly participated in our study and the chairman and organizing committee of the ultramarathon race. We also thank Ms. Fujii, T., Ms. Kubo, Y., Ms. Nakanishi, N., Ms Ito, Y., Ms. Higuchi, K., and Ms. Watanabe, M. for their technical assistance.

\section{References}

1. Alessio HM. Exercise-induced oxidative stress. Med Sci Sports Exerc. 1993;25:218-24.

2. Watson TA, Callister R, Taylor RD, Sibbritt DW, MacdonaldWicks LK, Garg ML. Antioxidant restriction and oxidative stress 
in short-duration exhaustive exercise. Med Sci Sports Exerc. 2005;37:63-71.

3. Nakamura H, Nakamura K, Yodoi J. Redox regulation of cellular activation. Ann Rev Immunol. 1997;15:351-69.

4. Holmgren A. Thioredoxin. Annu Rev Biochem. 1985;54:237-71.

5. Sen CK. Redox signaling and the emerging therapeutic potential of thiol antioxidants. Biochem Pharmacol. 1998;55:1747-58.

6. Bertini R, Howard OMZ, Dong HF, Oppenheim JJ, Bizzarri C, Sergi R, et al. Thioredoxin, a redox enzyme released in infection and inflammation, is a unique chemoattractant for neutrophils, monocytes, and T cells. J Exp Med. 1999;189:1783-9.

7. Zieker D, Fehrenbach E, Dietzsch J, Fliegner J, Waidmann M, Nieselt K. cDNA microarray analysis reveals novel candidate genes expressed in human peripheral blood following exhaustive exercise. Physiol Genomics. 2005;23:287-94.

8. Okamura K, Doi T, Hamada K, Sakurai M, Yoshioka Y, Mitsuzono R, et al. Effect of repeated exercise on urinary 8-hydroxy-deoxyguanosine excretion in humans. Free Radic Res. 1997;26:507-14.

9. Tagaya Y, Maeda Y, Mitsui A, Kondo N, Matsui H, Hamuro J, et al. ATL-derived factor (ADF), an IL-2 receptor/Tac inducer homologous to thioredoxin; possible involvement of dithiolreduction in the IL-2 receptor induction. EMBO J. 1989;8:75764.

10. Hayashi T, Ueno Y, Okamoto T. Oxidoreductive regulation of nuclear factor kappa-B in involvement of a cellular reducing catalyst thioredoxin. J Biol Chem. 1998;268:11380-8.

11. Makino Y, Okamoto K, Yoshikawa N, Aoshima M, Hirota K, Yodoi J, et al. Thioredoxin: a redox-regulating cellular cofactor for glucocorticoid hormone action. J Clin Invest. 1996;10:246977.

12. Almar M, Villa JG, Cuevas MJ, Rodriguez-Marroyo JA, Avila C, Gonzalez-Gallego J. Urinary levels of 8-hydroxydeoxyguanosine as a marker of oxidative damage in road cycling. Free Radic Res. 2002;36:247-53.

13. Radak Z, Pucsuk J, Boros S, Josfai L, Taylor AW. Changes in urine 8-hydroxydeoxyguanosine levels of super-marathon runners during a four-day race period. Life Sci. 2000;66:1763-7.
14. Child RB, Wilkinson DM, Fallowfield JL, Donnelly AE. Elevated serum antioxidant capacity and plasma malondialdehyde concentration in response to a simulated half-marathon run. Med Sci Sports Exerc. 1998;30:1603-7.

15. Scheele K, Herzog W, Ritthaler G, Wirth A, Weicker H. Metabolic adaptation to prolonged exercise. Eur J Appl Physiol Occup Physiol. 1979;41:101-8.

16. Tokudome S, Kuriki K, Yamada N, Ichikawa H, Miyata M, Shibata K, et al. Anthropometric, lifestyle and biomarker assessment of Japanese non-professional ultra-marathon runners. J Epidemiol. 2004;14:161-7.

17. Sumida $Y$, Nakashima $T$, Yoh $T$, Nakajima $Y$, Ishikawa $H$, Mitsuyoshi $\mathrm{H}$, et al. Serum thioredoxin levels as an indicator of oxidative stress in patients with hepatitis $\mathrm{C}$ virus infection. J Hepatol. 2000;33:616-22.

18. Dill DB, Costill DL. Calculation of percentage changes in volumes of blood, plasma, and red cells in dehydration. J Appl Physiol. 1974;37:247-8.

19. Wu HJ, Chen KT, Shee BW, Chang HC, Huang YJ, Yang RS. Effects of $24 \mathrm{~h}$ ultra-marathon on biochemical and hematological parameters. World J Gastroenterol. 2004;10:2711-4.

20. Petibois C, Paiva M, Cazorla G, Deleris G. Discriminant serum biochemical parameters in top class marathon performances. Jpn J Physiol. 2002;52:181-90.

21. Abdiu A, Nakamura H, Sahaf B, Yodoi J, Holmgren A, Rosen A. Thioredoxin blood level increases after severe burn injury. Antioxid Redox Signal. 2000;2:707-16.

22. Miyamoto S, Sakamoto T, Soejima H, Shimomura H, Kajiwara I, Kojima $\mathrm{S}$, et al. Plasma thioredoxin levels and platelet aggregability in patients with acute myocardial infarction. Am Heart J. 2003;146:465-71.

23. Mastaloudis A, Leonard SW, Yraber MG. Oxidative stress in athletes during extreme endurance exercise. Free Radic Biol Med. 2001;31:911-22.

24. Miyata M, Kasai H, Kawai K, Yamada N, Tokudome M, Ichikawa $\mathrm{H}$, et al. Changes of urinary 8-hydroxydeoxyguanosine levels during a two-day ultra-marathon race period in Japanese non-professional runners. Int J Sports Med. 2008;29:27-33. 